\title{
Primary subcutaneous cyst hydatic disease in proximal thigh: an unusual localisation: a case report
} Zafer Orhan*1, Hasan Kara1, Tolga Tuzuner ${ }^{1}$, Irfan Sencan² and Murat Alper ${ }^{3}$

Address: ${ }^{1}$ Department of Orthopaedics and Traumatology, Düzce Medical Faculty, Konuralp, Düzce, 14450, Turkey, ${ }^{2}$ Department of Infections Disease and Clinical Microbiology, Düzce, 14450, Turkey and ${ }^{3}$ Department of Pathology, Düzce Medical Faculty, Konuralp, Düzce, 14450, Turkey

Email: Zafer Orhan* - zorhan@excite.com; Hasan Kara - hasancara@hotmail.com; Tolga Tuzuner - tolgatuzuner@hotmail.com; Irfan Sencan - isencanibu@yahoo.com; Murat Alper - malper@ibuduzce-tip.edu.tr

* Corresponding author

Published: 07 November 2003

BMC Musculoskeletal Disorders 2003, 4:25
Received: 14 July 2003

Accepted: 07 November 2003

This article is available from: http://www.biomedcentral.com/147/-2474/4/25

(C) 2003 Orhan et al; licensee BioMed Central Ltd. This is an Open Access article: verbatim copying and redistribution of this article are permitted in all media for any purpose, provided this notice is preserved along with the article's original URL.

\begin{abstract}
Background: Musculoskeletal hydatidosis is very rare and represents $1 \%-5.4 \%$ of all cases of echinococcosis. On clinical basis, infection mimics a soft-tissue tumor, and the preoperative radiological diagnosis is very important to avoid biopsy.

Case Presentation: We report an unusual case of primary subcutaneous hydatidosis in proximity to vastus lateralis muscle. It was diagnosed according to the computed tomography appearance, clinical and pathological findings. A 43 year old female patient was admitted with a history of pain at proximal thigh for the last 30 days. On physical examination, a mass which was $4 \times 5 \mathrm{~cm}$ in diameter, painful and erythamatous, was palpated over greater trochanter. Sedimentation rate was $40 \mathrm{~mm}$ in the first hour. CT (Computed Tomography) scan demonstrated, a soft tissue mass with central cystic component in the subcutaneous tissue near vastus lateralis muscle.

Histopathological examination of the specimen revealed a pericystic structure, which consisted of connective tissue and scattered hyaline cells showing a necrotic basophilic structure that resembled a cuticular membrane. Treatment with high dose albendazole was conducted for 4 weeks.

Conclusions: This case illustrates that echinococcal disease should be considered in the differential diagnosis of every cystic mass in every anatomic location, especially when they occur in areas where the disease is endemic.
\end{abstract}

\section{Background}

Hydatidosis is known since Hippocrates. Echinococcosis or hydatic disease is caused by the tape worm, E. granulosus. The life cycle of E. granulosus is well described [1]. Echinococcosis has its highest prevalence in countries, where the common intermediate hosts, sheep and cattle, are raised (such as Middle East, Central Europe, Australia and South America) [2]. Hydatid disease mainly affects the pulmonary and digestive systems [3]. The liver is the most frequently involved organ $(75 \%)$, followed by the lung (15\%) and the rest of the body (10\%) [2]. (Primary involvement of muscle is very rare and has been reported in approximately $3 \%$ of all patients with hydatidosus [3]. It has been suggested that muscle provides a poor environment for the parasite because of the presence of lactic acid [4]. A review revealed cases involving the musculature of 
the chest wall[5], pectoralis major, sartorius[3], biceps brachii[4], and Sartorius[6].) Soft tissue hydatitosis is very rare. There are a few reports about primary subcutaneous hydatitosis in the extremities $[7,8]$. To our knowledge, subcutaneous involvement of echinococcal disease near the vastus lateralis muscle in the thigh has not been reported previously.

\section{Case report}

A 43 year old female patient was admitted with history of pain at proximal thigh for the last 30 days. There was no history of trauma in the proximal thigh region. No history of fever and weight loss was described.

On physical examination, a mass was palpated over greater trochanter. It was $4 \times 5 \mathrm{~cm}$ mass, painful, and erythematous. Range of motion of left hip was full and painless.
Investigations revealed that CBC (complete blood count), electrolytes, alkaline and acid phosphatese levels were within normal limits. Sedimentation rate was $40 \mathrm{~mm}$ in the first hour. X-ray of left hip was normal. Abdominal ultrasonography did not reveal any abnormality. CT scan demonstrated cystic structure close to vastus lateralis muscle (Figure 1). CT showed no involvement of lung and brain. Ultrasonographic examination of the mass showed a cystic structure. Hemoagglutination tests for echinococcosis and ELISA were negative. The patient underwent surgery for excision of the cyst. The diagnosis of Echinococcus granulosus infection was confirmed peroperatively after visualization of the cyst wall. Following irrigation of cystic cavity with hypertonic saline solution, the cyst wall was excised along with a portion of the vastus lateralis muscle.

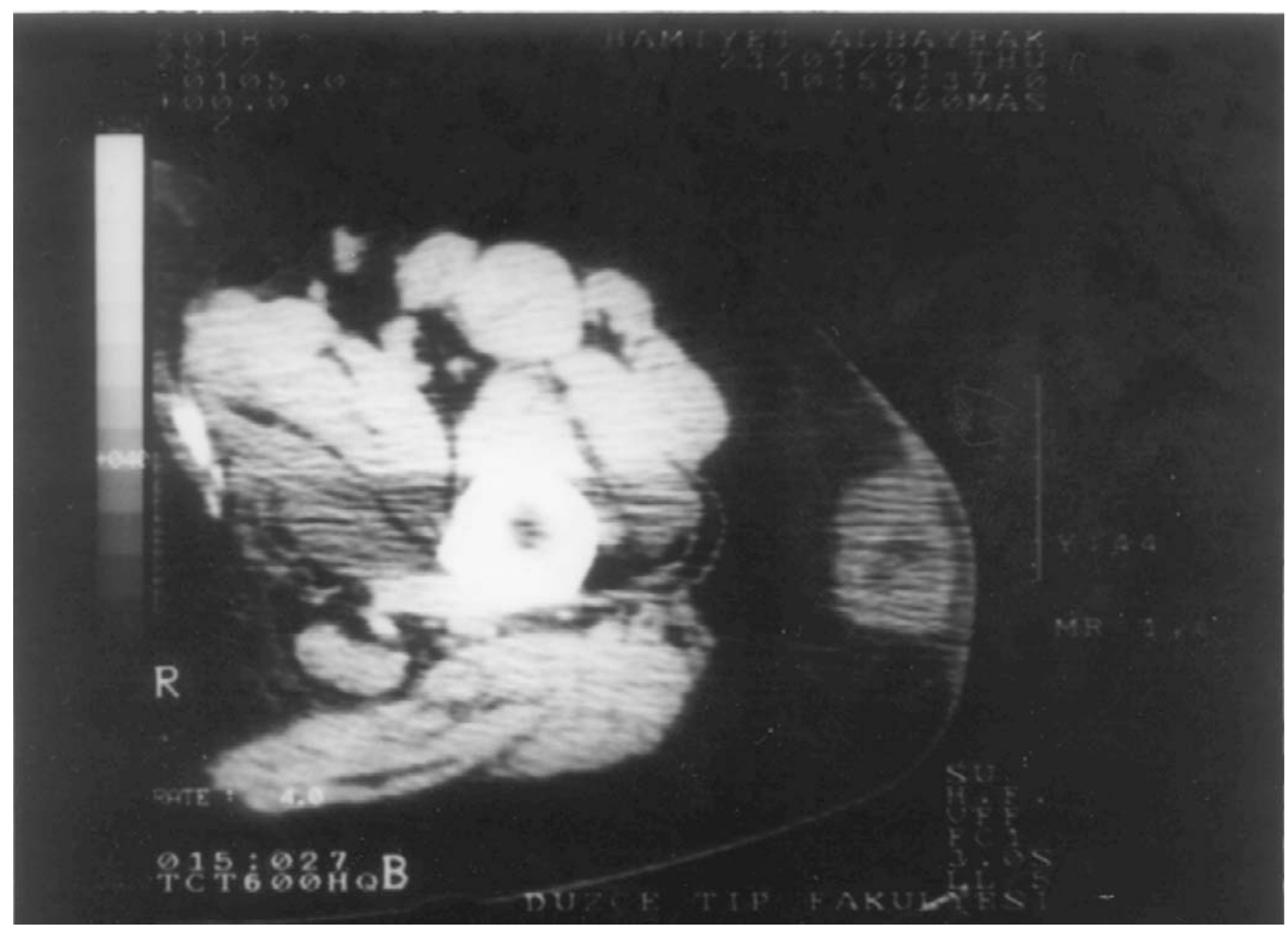

Figure I

Computed Tomographic view of primary subcutaneous hydatic cyst in proximal thigh. 


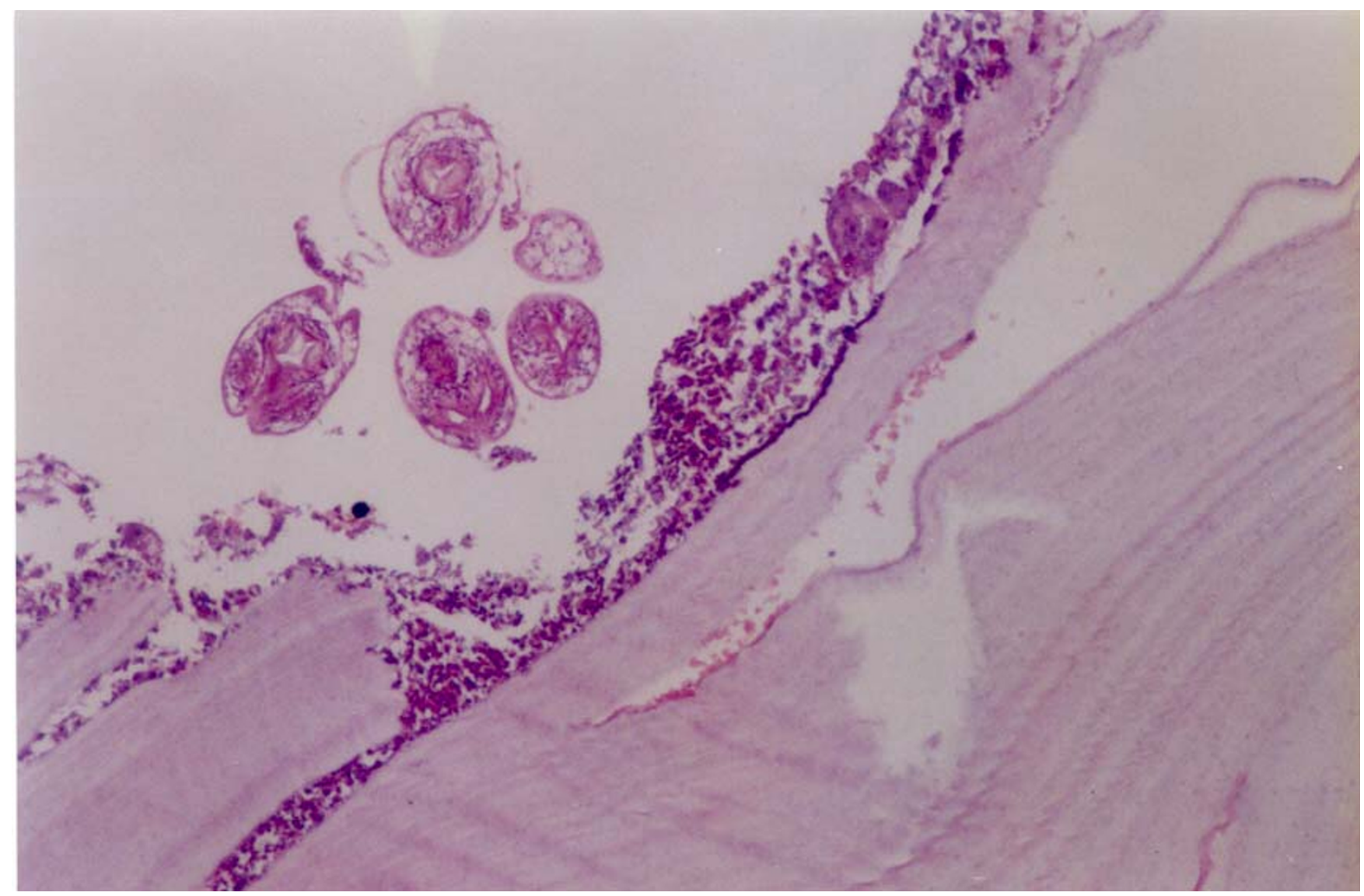

Figure 2

The scoleces are seen in histopathologic section of hydatic cyst.

Histopathological examination of the specimen revealed fibrosis, necrosis, histiocyte cell clusters, mixed type of inflammatory cells, fibroblastic activity and vascular proliferations in adipose and connective tissues. A pericystic structure which consisted of connective tissue and scattered hyaline cells showed a necrotic basophilic structure which resembled cuticular membrane. Scoleces were also detected within the surgical specimen. Hemorrhagic areas were seen within the periphery of cyst. (Figure 2). A high dose of albendazole was initiated for 4 weeks, and a favorable response was obtained. During the follow-up period, chest radiography, abdominal and proximal thigh ultrasonography (US), routine blood biochemistry (glucose, ALT, AST, alkaline phosphatase, blood urea nitrogen, serum creatinine, total protein, albumin and indirect hemoglutination test were performed.

\section{Discussion}

Incidence of musculoskeletal hydatidosis is not clear. According to authors, incidence of musculoskeletal echi- nococcosis including involvement of subcutaneous tissue is $1 \%-5.4 \%$ among all cases of hydatid disease $[9,10]$. Soft-tissue hydatid cysts occur in $2.3 \%$ of cases reported from endemic areas. They are usually associated with involvement of other solid organs.

Diagnosis of echinococcosis should be considered when slowly growing soft tissue is present in patient from a rural area especially endemic countries. Before surgical excision or biopsy and extirpation of cyst, diagnosis of echinococcosis should be excluded to avoid leakage of cyst contents and the accompanying risks of anaphylaxis. US is useful in diagnosis, showing the size, localisation and type of the cyst. The sensitivity of US (Ultrasonography) is $95 \%$, and if vesicular fibrils are present, the sensitivity of US increases to $100 \%$. CT scan should be performed in suspicious cases or in order to determine the technique of surgery with demonstration of the relationship to adjacent organs [11]. 
Preoperative diagnosis of musculoskeletal E. granulosis infection is difficult clinically and radiologically. It may resemble any soft tissue tumor. MRI is capable of adequately demonstrating most features of hydatid disease, with the exception of calcifications [12]. Garcia-Diez reported MRI examinations of 7 patients with musculoskeletal hydatidosis. Typical signs of hydatidosis were multivesicular lesions with or without hypointense peripheral ring (rim sign). According to the presence of viable daughter cysts MRI conveyed as high signal intensity or low signal intensity on T2-weighted images [13]. There is controversy about the value of MRI in diagnosing the vitality of the cyst. Hypointensity of daughter cysts compared with the matrix of the mother cyst on T2weighted images is a clue for the death of the parasite [1416]. Proton density-weighted images generated by gradient echo sequences as a sign of biological activity was suggested by Tekkok et al [15].

Echinococcosis resembles a benign neoplasm in many ways. In order to prevent serious complications, It should be diagnosed be made before any therapeutic intervention. The diagnosis is based on the history of exposure in an endemic area and US, CT findings [17]. The diagnosis can be supplemented by specific Ig $\mathrm{G}$, complement fixation, indirect fluorescent, and ELISA tests. The sensitivity of various serological tests used for hydatid disease varies from 64 to $87 \%$. False positivity of Casoni skin test was reported in infestations of tenia saginata and other helmints because of cross reactions. The specificity of Casoni skin test is low because of this high, $40 \%$ false positivity. ELÝSA/ Western blood serology is $80-100 \%$ sensitive and $88-96 \%$ specific for liver cyst infestation, but less sensitive for lung (50-56\%) or other organ involvement (25-26\%) [18]. After surgical excision of the cyst, reagenic antibody (I g E) titers decrease and become negative after 1-2 years. If titers do not decrease, recurrence of echinococcosis should be considered. Hydatic serology is only valuable when it is positive, negative serologic test does not exclude the diagnosis.

If the cyst is not complicated, serology is less sensitive but it may be useful for controlling the recurrence of cyst.

Cure depends on total or subtotal surgical excision of the cysts. Echinococcosis can be prevented by public health eradication programs.

E. granulosis is best treated by complete excision of the intact cyst. If it is impossible to excise a large cyst en bloc, the cyst has to be drained intraoperatively, irrigated with a scolecidal agent such as hypertonic saline, and then excised [4]. Rupture of the parent cyst increases the likelihood of recurrent infestations. In addition, leakage of the cyst contents may cause anaphlactic shock $[4,19]$.
This case illustrates that echinococcal disease should be considered in the differential diagnosis of every cystic mass in any anatomic location, especially when they occur in areas where the disease is endemic.

\section{Competing Interests}

None declared.

\section{Acknowledgements}

"Written consent was obtained from the patient or their relative for publication of the patient's details."

\section{References}

I. Lewall DB and Mc Corkell SS: Hepatic echinococcal cysts: Sonographic appearance and classification. Radiology 1985, 155:773-775.

2. Saidi F: Surgery of Hydatic Disease. Saunders, Philadelphia 1976, 3:3I-I55.

3. Rask MR and Lattig GJ: Primary intramuscular hydatidosis of the sartorius. J Bone Joint Surg Am 1970, 52:582-584.

4. Duncan GJ and Tooke SMT: Echinococcus infestation of the biceps brachii. Clin Otrhop 1990, 261:247-250.

5. Alvarez-Sala R and Caballero P: Echinococcus cyst as a cause of chest wall tumor. Ann Thorac Surg 1987, 43:689-690.

6. Tatari H, Baran Ö, Sanl da $\breve{g} T$, Göre $O$, Ak D, Manisal $M$ and Hav tç oğlu H: Primary intramuscular hydatidosis of supraspinatus muscle. Arch Orthop Trauma Surg 200I, I 21 :93-94.

7. Chevalier X, Rhamouni A, Bretagne S, Martigny J and Piet BL: Hydatid Cyst of the Subcutaneous Tissue Without Other Involvement: MR Imaging Features. AJR 1994, 163:645-646.

8. Memis A, Arkun R and Bilgen I et al:: Primary soft tissue hydatid disease:report of two cases with MRI characteristics. Eur Radiol 1999, 9(6): I I0I-II 03.

9. Desnuelle C, Kleisbauer JP and Serratice G: Kyste hydatique musculaire de la cuisse. Diagnostic pre-operatoire. Sem Hop Paris 1986, 62:1826-28.

10. Sallazo M: Idatidosi musculare. Minerva. Ortop 1970, 2 I: 105-108.

II. Fikry T, Harfaoui A, Sibai H and Zryouil BL: Echinococcose musculaire primitive. J Chir 1997, I34(7-8):325-328.

12. Von Sinner $W$, Strake $L$, Clark $D$ and Sharif $H$ : MR imaging in hydatid disease. AJR I99I, 157:74I-745.

13. Diez G, Mendoza LHR, Villacampa VM, Cozar M and Fuertes MI: MRI evaluation of soft tissue hydatid disease. Eur Radiol 2000, I0:462-466.

14. Martin J, Marco V and Zidan A et al.: Hydatid disease of the soft tissues of the lower limb:findings in three cases. Skeletal Radiol 1993, 22:5II-5I4.

I5. Tekkok IH and Benli K: Primary spinal extradural hydatid disease: report of a case with magnetic resonance characteristics and pathological correlation. Neurosurgery 1993, 33:320-323.

16. Jena A, Tripathy RP and Jain AK: Primary spinal echinococcosis causing paraplegia:case report with MRI and pathologic correlation,. AJNR I99|, I 2:560.

17. Resnick $D$ and Niwayama G: Diagnosis of bone and joint disorders. Secondth edition. W.B. Saunders company; 1988:2738-2739.

18. Charles King H: Cestodes. In; Principles and practice of Infectious Diseases, NY Fourthth edition. Edited by: Gerald L Mandell, John E. Bennett, Raphael Dolin. Churchill Livingstone inc; 1995:2543-2553.

19. Rao S, Parikh $S$ and Kerr R: Echinococal infestation of the spine in North America. Clin Orthop 1991, 52:582-584.

\section{Pre-publication history}

The pre-publication history for this paper can be accessed here:

http://www.biomedcentral.com/1471-2474/4/25/prepub 